\title{
Neurology in ancient faces
}

\author{
O Appenzeller, J M Stevens, R Kruszynski, S Walker
}

New Mexico Health Enhancement and Marathon Clinics Research Foundation 361 Big Horn Ridge, NE Albuquerque, NM 87122-1424, USA O Appenzeller

National Hospital for Neurology and Neurosurgery, Lysholm Department of Radiology, Queen Square, London, UK J M Stevens

Human Origins Group, Department of Palaeontology, Natural History Museum, London, UK

R Kruszynski

The British Museum, Department of Greek and Roman Antiquities, London, UK

S Walker

Correspondence to: Dr O Appenzeller ottoarun12@aol.com

Received 2 May 2000 and in revised form 20 November 2000 Accepted 22 November 2000

\begin{abstract}
Background-Clinical paleoneurology is almost non-existent, but recognition of neurological diseases in ancient people might be possible by scrutinising portraits apparently representing people as they appeared in life.
\end{abstract}

Methods-About 200 mummy portraits painted in colour at the beginning of the first millennium were examined. Thirty two skulls excavated at Hawara in the Fayum (northern Egypt), where most of the portraits were found were measured, and nine caliper measures on each side of the skulls were taken. The right/left ratios were statistically analyzed by analysis of variance (ANOVA). One skull was subjected to 3D CT scanning and transilluminated.

Results-Two patients were found with progressive facial hemiatrophy (ParryRomberg syndrome), three with deviations of the visual axes (tropia) and one with oval pupils (corectopia).

Conclusions-Clinical paleoneurology is possible in the absence of a living nervous system. The patients probably had focal epilepsy, hemiplegic migraine, and autonomic nervous system dysfunction. (F Neurol Neurosurg Psychiatry 2001;70:524-529)

Keywords: clinical paleoneurology; mummy portraits; progressive facial hemiatrophy; tropia; autonomic nervous system

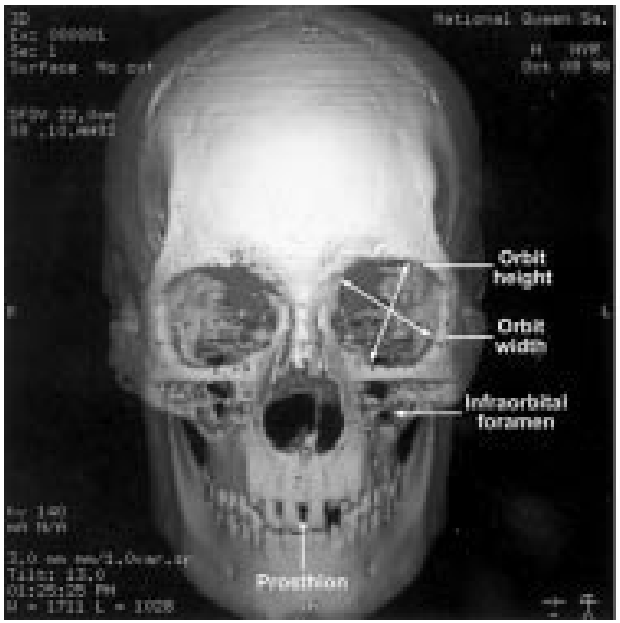

Figure 1 Caliper measurements taken on 32 skulls excavated at Hawara, used for statistical analysis, and illustrated on the $3 D$ CT surface rendering of the skull of the portrait, catalogue number 21, British Museum EA 74707.

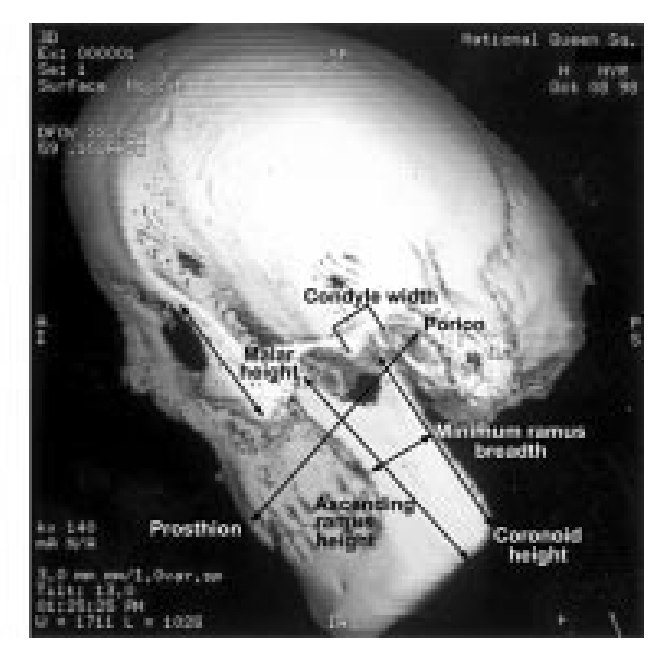

Paleopathology is a well established science. ${ }^{1}$ By contrast, paleoneurobiology, a term encompassing the study of neural tissues from mummified remains, is almost non-existent. ${ }^{2}$ This is partly due to the poor preservation of neural tissues by natural or artificial mummification. ${ }^{3}$ Recognising neurological diseases in ancient humans might be possible by scrutiny of their portraits and comparing the images to surviving skeletal remains. Painted portraits of Egypt's Roman period have survived and have been called "the most remarkable products of the ancient world". ${ }^{4}$ These portraits, many of great artistic merit, were painted about 2000 years ago; they were part of the funerary practices in northern Egypt and arose in response to a concern for the wellbeing of the dead. ${ }^{5}$ One feature of Egyptian civilization was the conviction that life after death was inevitable. To survive death and thereby facilitate the transition to the next life required a passage from earthly to the other life in both spiritual and physical forms. The corpse was preserved by mummification and served as a foundation for the spiritual aspects.

The funerary portraits were commemorative expressions of respect for distinguished citizens at Rome. During the Republic these portraits were restricted to the nobility and to the families of serving magistrates. By the time of the Roman Empire the portraits were no longer restricted by class or office but became a means of proclaiming loyalty to the reigning emperor. 
In Egypt, a province of the Roman Empire, the portraits were made for the specific purpose of covering the head of the mummy with a likeness of the deceased. The practice of mummy portraiture appeared in Egypt in the middle of the 1st century and continued for some 200 years.

Dating of portraits. Throughout the Empire attempts were made to follow closely court fashions in hairstyle and physiognomy at Rome. Thus, by comparing objects of known date from other parts of the Empire it is possible to show that the hairstyle, clothing, and jewelry depicted in a portrait belong to a specific period and in many cases dating is attempted within a decade. ${ }^{6}$

Timing of portraiture. Whereas many portraits are of relatively young people, a few show older subjects. Because most radiological studies of the few complete mummies with their portraits in place showed corresponding skeletal features of age and sex, it is thought that most portraits were painted before the imminent death of the subject. ${ }^{6}$

The reflection of light from the cornea, represented by specks of white in many mummy (and modern) portraits is, however, not always present. Some portraits lack the reflected lustre in the eye and give the impression of a likeness of a dead subject.?

Discovery of mummy portraits. Pietro della Valle (1586-1652), an Italian traveller first published two mummy portraits in his travelogue which appeared in 1650 . In the 1880 s
Theodor Graf (1840-1903) bought up all portraits discovered at about that time near er-Rubayat (north east Fayum). Flinders Petrie (1853-1942), an eminent British archeologist, discovered a large Roman cemetery at Hawara in south east Fayum and made the first careful recording of many mummy portraits in an archeological context. Because of the dominance of these two areas, the mummy portraits have also been called Fayum portraits. ${ }^{8}$

Unfortunately, portraits preserved separately from the mummies can only rarely be associated with specific remains. Thus, only 19 skulls, presently kept at the Natural History Museum in London, can, with assurance, be linked to specific portraits. The museum, nevertheless, has additional skulls, which were all excavated at Hawara.

Corneal reflections. The routine clinical neurological examination includes the inspection of the light reflection in the cornea for asymmetries. Since the axes of the eyes are parallel, deviations of the light reflections are easily recognised. The diagnosis of oculomotor abnormalities in portraits is dependent on the artistic use of white specks to give the eye a lifelike quality. ${ }^{7}$ Artists depict deviations of the light reflections by placing the white specks representing the corneal reflection of light in asymmetric positions.

We examined mummy portraits for signs of neurological disease. We report herein the successful identification of neurological disorders

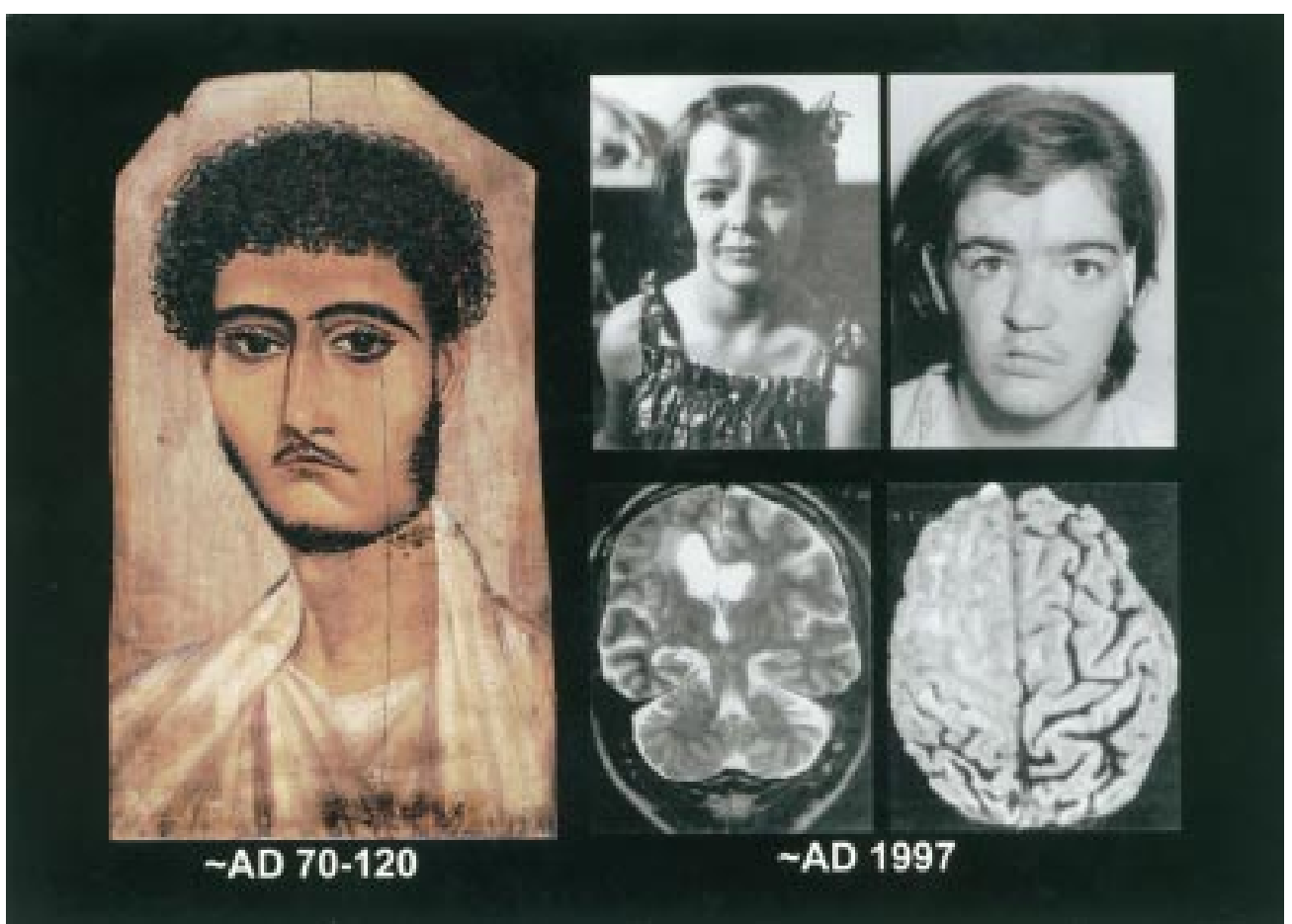

Figure 2 Portrait of a youth (left) showing right sided progressive facial hemiatrophy (British Museum EA 74707, copyright of the British Museum; with permission). Two photographs of a patient taken 20 years apart and her MRI (right) with right sided progressive facial hemiatrophy. Right ventricular enlargement, loss of sulci at the convexity, subcortical hyperintensity, and on surface rendering (bottom right inset), loss of sulci in the right frontal lobe can be seen (from Dupont et al ${ }^{14}$ with permission). Note the similar facial features including the strong eyebrows extending on the left across the bridge of the nose, the lowering of the left corner of the mouth and moustache in the portrait and photograph, the shape of the chin and the similarity in shape and direction of the labio-mental groove on the left (upper right inset). It is to be noted that these facial features which enabled the diagnosis of progressive facial hemiatrophy to be made in both patients are on the left side of the portrait and photograph whereas the neurological concomitants of progressive facial hemiatrophy in the patient and the skeletal abnormalities in the ancient skull are on the right. 

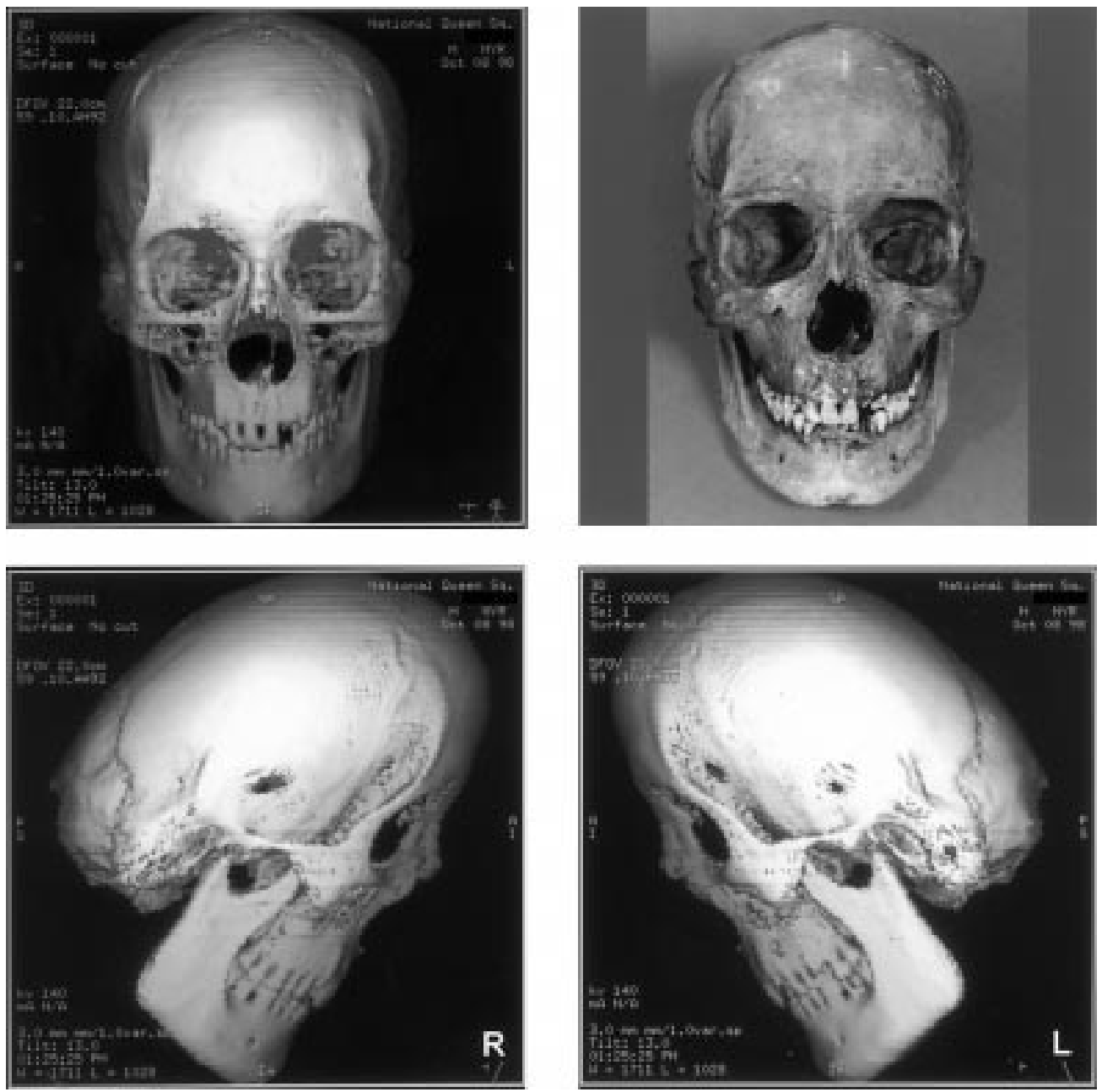

Figure 3 Three dimensional CT with surface rendering and a picture (upper right) of the skull belonging to portrait, British Museum EA 74707. The smaller right orbit and asymmetric zygomatic arches are clearly visible.

in portraits of human beings that lived about two millennia ago.

\section{Methods}

THE PORTRAITS

About 200 mummy portraits and other images exhibited in 1997 at the British Museum, London, were examined for signs of neurological

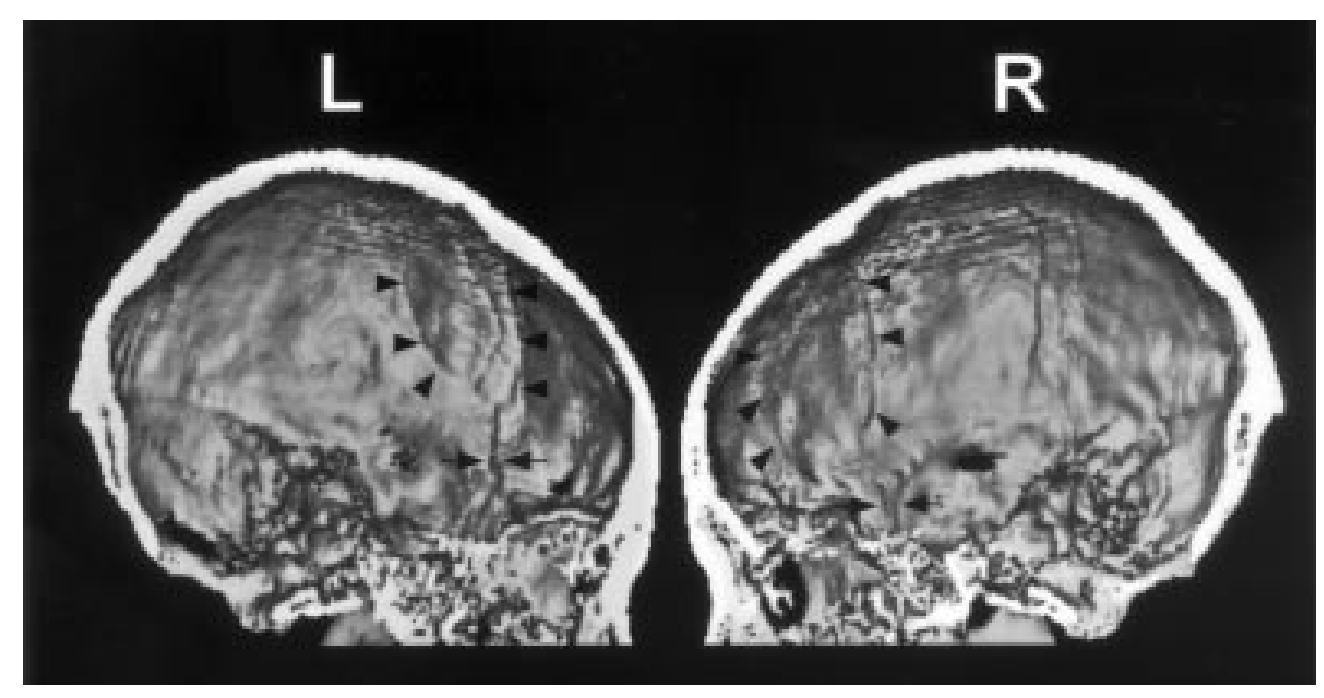

Figure 4 Paucity of gyral imprints (arrow heads) and truncated middle meningeal artery groove (arrows) on right inner

Figure 4 Paucity of gyral imprints (art
table (3D-CT, same skull as in fig 3). disease. Additional mummy portraits, on permanent exhibit at the Metropolitan Museum of Art in New York, were also scrutinised.

EXAMINATION OF SKULLS

Thirty two skulls excavated by Flinders Petrie near the turn of the 20th century at Hawara, 


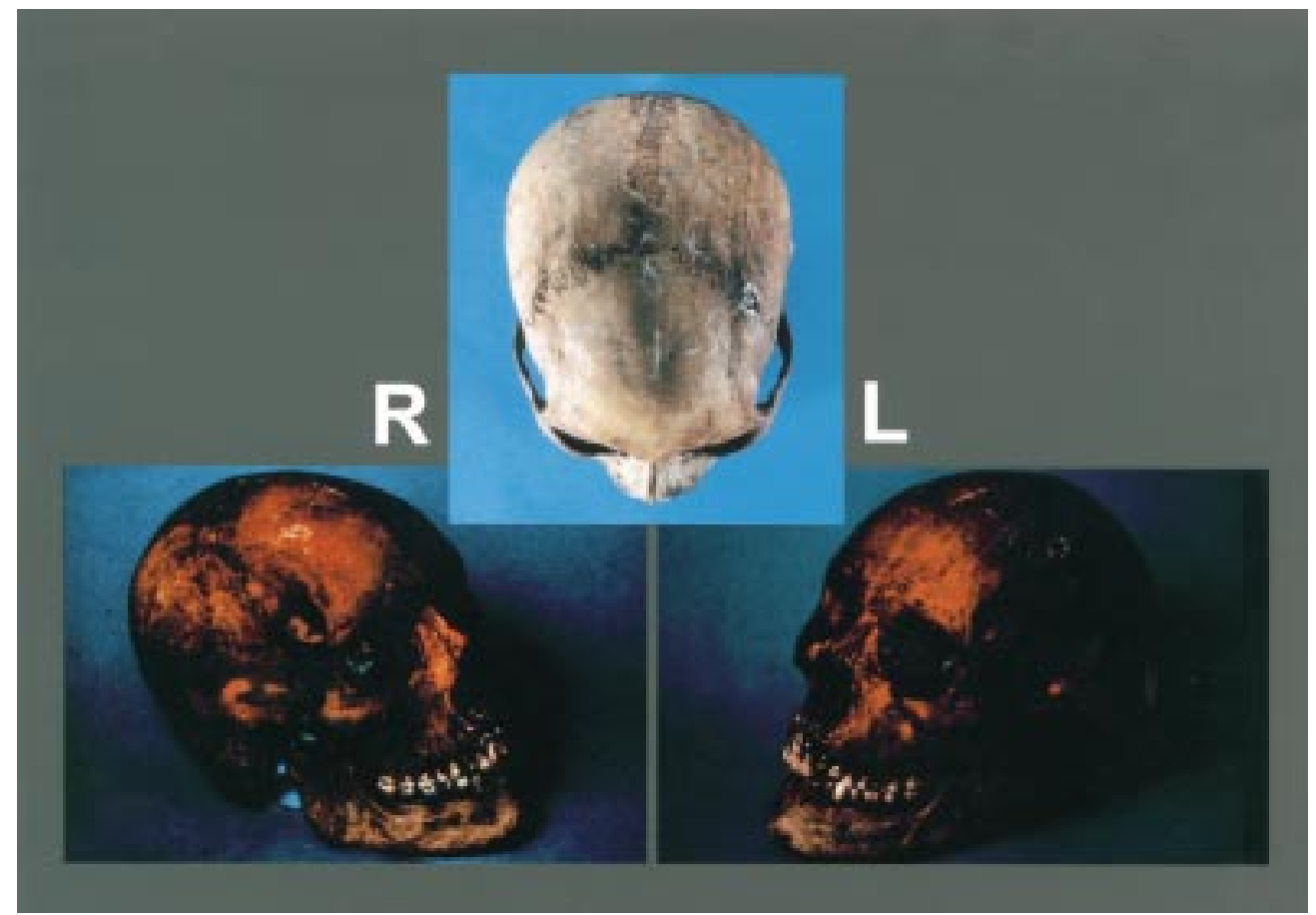

Figure 5 Surface view of skull (British Museum EA 74707) and transillumination (lower panels) showing larger area of transillumination in the right frontotemporal-parietal area and asymmetry of zygomatic arches.

now stored at the National History Museum London, were examined. Nine measurements on each side, using standard calipers, were made (fig 1). To avoid variability in skull size, right/left ratios of the measurements were used for statistical analysis by $\chi^{2}$ test.

One skull that could, with certainty, be associated with a portrait exhibited at the British Museum (British Museum EA 74707, Ancient Faces Catalogue No 21) was of particular

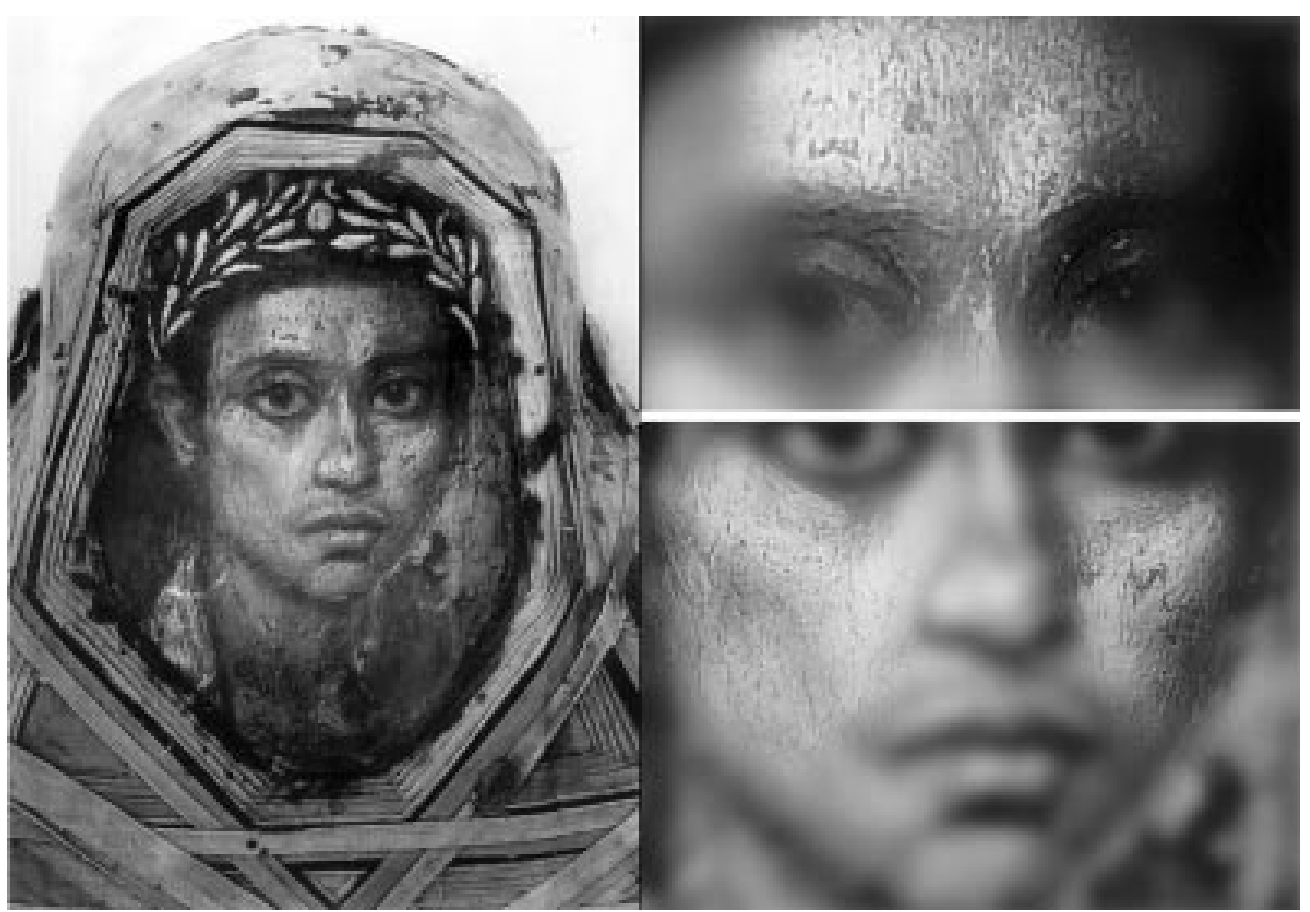

Figure 6 Photograph of a mummy of a youth (left). En coup de sabre lesion (midline) in the left panel, magnified (upper right) and atrophy of right zygomatic region (magnified lower right). Note the linear depression, slightly curved to the right beginning just above the nose suggestive of a scar inflicted by a sabre (Metropolitan Museum of Art, New York, Department of Egyptian Art, 11.139; with permission).

neurological interest. This skull was transilluminated through the foramen magnum and photographed in a darkened room after repeated flashes with time exposure. The extent of the transillumination when compared on the two sides gave an indirect measurement of the relative thickness of the skull bones. This skull was also subjected to 3D CT scanning at the National Hospital for Neurology and Neurosurgery, Queen Square, London. 


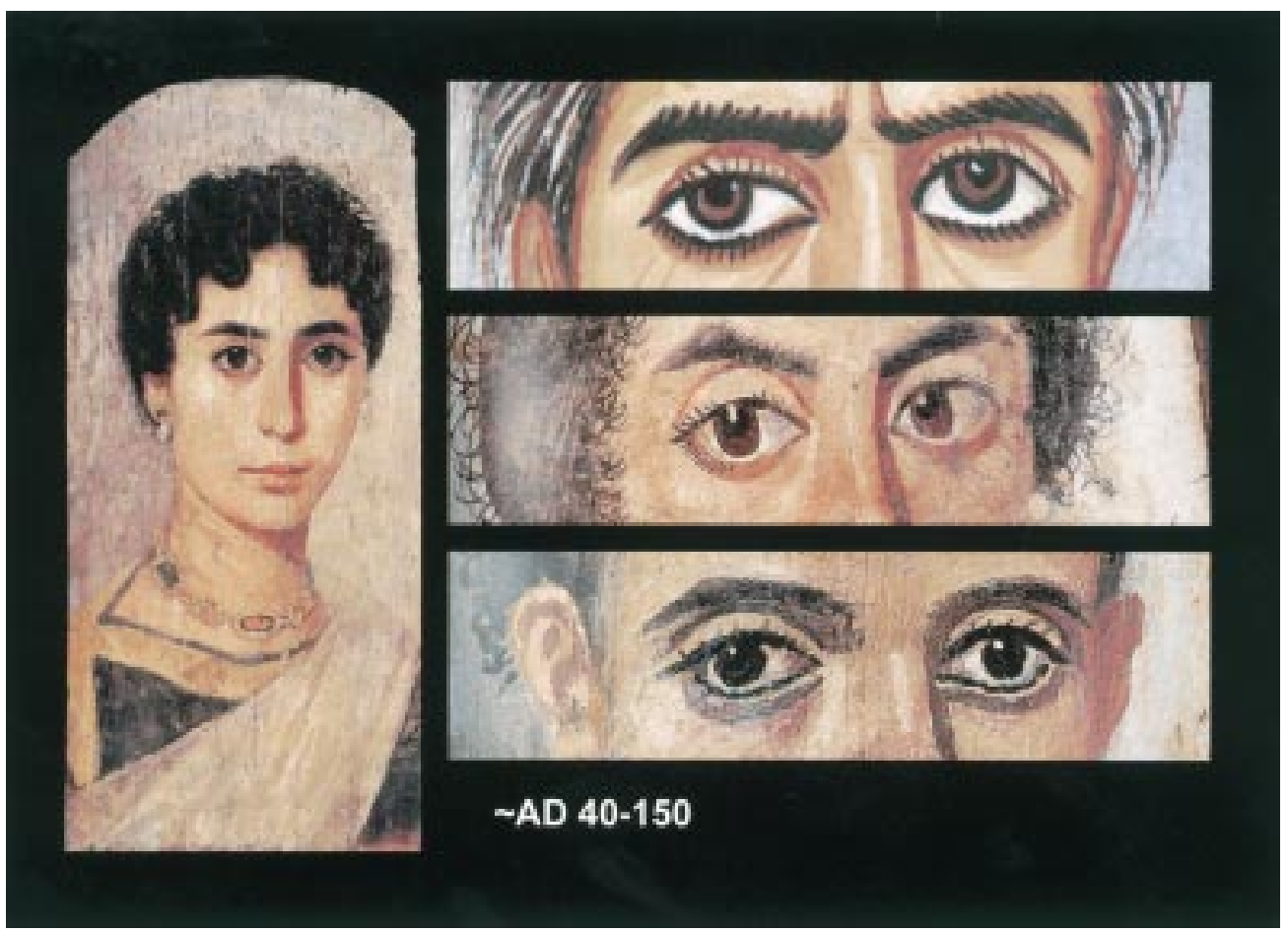

Figure 7 Deviation of visual axes of the eyes (tropia) and corectopia in mummy portraits. A woman in a blue tunic (British Museum EA 65346) on the left to show, in this accomplished portrait, the lifelike quality of the eyes. Esotropia and slight exophthalmus-left (upper right) in an elderly woman (British Museum GRA 1890.9-20.1). Esotropia-left and bilateral oval pupils (corectopia) in a middle aged woman (middle right) (F Paul Getty Museum 81.AP.29). Exotropia-right (lower right) in a portrait of a boy ( $(F$ Paul Getty Museum 78.AP.262) (copyright of the British Museum; with permission.

CORNEAL REFLECTIONS

The mummy portraits were examined for esotropia, exotropia, hypertropia, and hypotropia using the position of the white flecks of paint in the corneas as a guide.

\section{Results}

The portrait of a young man in encaustic on limewood excavated by Petrie at Hawara in 1888 (EA 74707, Ancient Faces Catalogue No 21) suggested that he had progressive facial hemiatrophy. This portrait was dated to early Flavian-Trajanic times by the trim of the beard and the style of the drapery. The description in the catalogue emphasises the long eyebrows and prominent upper lashes. The "unsatisfactory appearance" of the mouth and chin was thought to represent a "facial tic" rather than an "inability on the part of the painter" (fig 2).

The 3D CT of the skull showed obvious orbital asymmetry (fig 3) and a paucity of gyral imprints on the inner table on the right (fig 4).

This skull also showed a greater area of transillumination on the right implying thinness of bones on that side (fig 5).

Chi square analysis of the right/left ratios of the nine measures from the 32 skulls excavated at Hawara showed that the skull belonging to the young man (EA 74707, Ancient Faces catalogue No 21) was significantly different $(p<0.001)$ from all other skulls excavated at the same site. The orbit height and width were smaller on the right and the right infraorbital foramen was larger ( $7 \mathrm{~mm}$ compared with 4.9 $\mathrm{mm}$ on the left).

Two additional skulls (without portraits) were also statistically different from other skulls but the differences were in measures reflecting lower facial bone sizes.

One portrait, exhibited at the Metropolitan Museum of Art in New York, suggested that the subject had progressive facial hemiatrophy of the en coup de sabre variety (fig 6). ${ }^{10}$

A few portraits show obvious deviations of the visual axes of the eyes as judged by the white specks of paint representing the reflection of light from the cornea. One portrait (J Paul Getty Museum 81.AP.29) also shows oval pupils (corectopia, fig 7 ).

\section{Discussion}

We have grounds for the diagnosis of progressive facial hemiatrophy on the right in the youth depicted in portrait EA 74707, Ancient Faces Catalogue No 21, exhibited at the British Museum in 1997. This diagnosis was based on the usual criteria: localised atrophy of skin and subcutaneous tissues suggested by the facial features and atrophy of underlying bony structures. Additional features supporting this diagnosis are the ipsilateral smallness in orbit height and width and the larger infraorbital foramen on the right attesting to the asymmetry of facial bones. Moreover the relative lack of gyral impressions on the inner table of the skull implies a paucity of sulci in the underlying cortex. The diagnosis of progressive facial hemiatrophy of the en coup de sabre variety in the portrait from the Metropolitan Museum of Art in New York (fig 6) is based entirely on the appearance of the youth, there being no skull available for examination. The diagnosis in this case is, therefore, less certain. Scleroderma with streak-like focal skin atrophy on the 
forehead resembles a scar after a cut inflicted by a sabre, hence the designation of this variety of progressive facial hemiatrophy as en coup de sabre. Many patients with this disorder are thought to have "abortive progressive facial hemiatrophy". ${ }^{10}$

The clinical identification of heterotropias is in part dependent on having the light source in alignment with the observer's eye. We cannot know if the anonymous portraitists 2000 years ago aligned the light with their eyes or if it came from another direction. In the latter situation the decentration of the corneal reflection may be an artifact. However, such artifactual displacement affects both eyes equally if the visual axes remain parallel. The portraits are of superb artistic quality, ${ }^{4}$ the faithful rendition of exophthalmos together with unilateral esotropia (fig 7), and the rarity of tropias among the more than 200 Fayum portraits examined all argue against artifactual heterotropias.

Progressive facial hemiatrophy was first described in 1825 by Parry $^{11}$ and further defined by Romberg in $1846 .^{12}$ This condition is also known as the Parry-Romberg syndrome. Neurological symptoms associated with progressive facial hemiatrophy include focal epilepsy. ${ }^{13}$ Ipsilateral hemispheric atrophy, hypodensities and calcifications, white matter abnormalities, poorly defined sulci, and abnormal meningocortical zones (as shown by contrast enhancement on CT) have also been noted. Cortical dysgenesis has been proposed as one mechanism to explain the neurological accompaniments of this disorder and the association of abnormalities arising simultaneously in facial and ipsilateral hemispheric structures. ${ }^{14}$ In one case of progressive facial hemiatrophy with the coup de sabre deformity cortical biopsy showed lymphocytic perivascular cuffing with microglial nodules. ${ }^{15}$ In another case circulating antibodies against brain stem adrenergic neurons have been found and the condition attributed to brain stem sympathetic dysregulation. ${ }^{16}$ Pupillary abnormalities, enophthalmos, eyebrow thinning, and other disturbances of autonomic function have also been reported ${ }^{17}$ and some patients with progressive facial hemiatrophy have been treated by periarterial sympathectomy. ${ }^{18}$ Intracranial vascular malformations, ${ }^{17}$ and contralateral hemiplegic migraine have been recognised in progressive facial hemiatrophy. ${ }^{19}$

The portrait with oval pupils (corectopia) in the exhibition at the British Museum in 1997 suggests that the subject had either diabetes mellitus or corticobasal degeneration. Twenty four per cent of diabetic patients have corectopia. In these patients corectopia is associated with abnormalities in heart rate variability, a sign of autonomic dysfunction. ${ }^{20}$ Similarly in corticobasal degeneration corectopia is associated with pupillary denervation-super sensitivity, which implies a midbrain origin for the autonomic dysfunction. ${ }^{21}$
Neurological symptoms and signs are normally evaluated during life. We show here that, although the patients died about 2000 years ago, the probability that they had focal epilepsy, hemiplegic migraine, deviation of the visual axes (tropia), corectopia, and autonomic nervous system dysfunction is very high. Thus, clinical paleoneurology is possible without the presence of a living nervous system.

This work was supported by New Mexico Health Enhancement and Marathon Clinics Research Foundation with assistance from NIH grant No IHSEP-02. We are grateful to Dr Clifford from NIH grant No IHSEP-02. We are grateful to Dr Clifford Qualls for statistical analysis of measurements of the skulls from politan Museum of Art, New York for the photograph of a complete mummy of a youth (MMA Department of Egyptian Art, 11.139).

1 Aufderheide C, Rodriguez-Martin C. The Cambridge encyclopedia of human paleopathology. Cambridge University Press, Cambridge UK. 1998.

2 Hoyle CHV, Thomas PK, Burnstock G, Appenzeller O. Immunohistochemical localisation of neuropeptides and nitric oxide synthase in sural nerves from Egyptian mummies. F Auton Nerv Syst 1997;67:105-8

3 Appenzeller O, Aufderheide AC. Paleoneurobiology and the autonomic nervous system. In: $\mathrm{O}$ Appenzeller, ed. Handbook of clinical neurology. The autonomic nervous system. Part I. Normal functions. 1999;74:181-97.

4 Davis WV. Preface. In: Walker S, Bierbrier M, eds. Ancient faces, mummy portraits from Roman Egypt. London: Trustees of the British Museum, 1997:7.

5 Taylor J. Before the portraits: burial practices in pharaonic Egypt. In: Walker S, Bierbrier M, eds. Ancient faces, mummy portraits from Roman Egypt. London: Trustees of the British portraits from Roman E.

6 Walker S. Mummy portraits and Roman portraiture. In: Walker S, Bierbrier M, eds. Ancient faces, mummy portraits from Roman Egypt. London: Trustees of the British Museum, 1997:14-16.

7 Miller J. On reflection. In: Miller J, ed. On reflection. London: National Gallery, 1998:37.

8 Bierbrier M. The discovery of mummy portraits. In: Walker S, Bierbrier M, eds. Ancient faces, mummy portraits from Roman Egypt. London: Trustees of the British Museum, 1997:23-24.

Parlasca K. Mumienporträts und verwandte Denkmäler. Wiesbaden: K Parlasca, 1966

10 Cory RC, Clayman DA, Faillace WJ, et al. Clinical and radiologic findings in progressive facial hemiatrophy (Parry-Romberg syndrome). Am f Neuroradiol 1997;18: 751-7.

11 Parry $\mathrm{CH}$. Collections from the unpublished medical writings of the late Calef Hillies Parry. London: Underwritings of the late
woods, $1825: 478$.

12 Romberg MH. Klinische Ergebnisse. Berlin: Förstner, 1846: $75-81$.

13 Wolf SD, Verity MA. Neurological complications of progressive facial hemiatrophy. $\mathcal{F}$ Neurol Neurosurg Psychiatry 1974;37:997-1004.

14 Dupont S, Catala M, Hasboun D, et al. Progressive facial hemiatrophy and epilepsy: a common underlying dysgenetic mechanism. Neurology 1997;48:1013-18.

15 Pupillo G, Andermann F, Dubeau F. Linear scleroderma and intractable epilepsy: neuropathologic evidence for a chronic inflammatory process. Ann Neurol 1996;39:277-8.

16 Lonchampt P, Emile J, Pélier-Cady MC, et al. Central sympathetic dysregulaton and immunological abnormalities in a case of progressive facial hemiatrophy (Parry-Romberg disease). Clin Auton Res 1995;5:199-204.

17 Miedziak AI, Stefanyszyn M, Flanagan J, et al. ParryRomberg syndrome associated with intracranial vascular malformations. Arch Ophthalmol 1998;116:1235-7.

18 Rogers BO. Progressive facial hemiatrophy (Romberg's disease): a review of 772 cases. In: Transactions of the 3rd international congress of plastic surgery. Washington: Excerpta Medica Foundation, 1963:681. (International congress series No 66.)

19 Terstegge K, Henkes H, Kunath B, et al. Zerebrale Manifestationen der progressiven fazialen Hemiatrophie (Romberg-Erkrankung). Radiologe 1993;33:585-95.

20 Isotani $\mathrm{H}$, Fukumoto $\mathrm{Y}$, Kitoaka $\mathrm{H}$, et al. Oval pupils in patients with diabetes mellitus: examination by measurement of the dark-adapted pupillary area and pupillary light reflex. Diabetes Res Clin Pract 1995;29:43-8.

21 Hirabayashi H, Takahashi W, Shinohara Y, et al. Pupillary abnormalities in a patient with clinically diagnosed corticobasal degeneration. Rinsho Shinkeigaku 1997;37:344-6. 